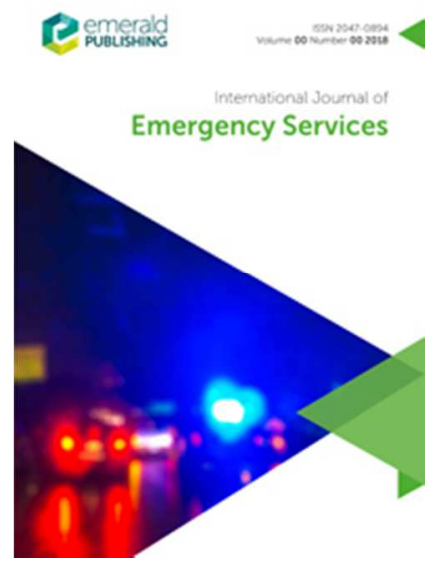

The role of psychological screening for emergency service responders

\begin{tabular}{|r|l|}
\hline Journal: & International Journal of Emergency Services \\
\hline Manuscript ID & Draft \\
\hline Manuscript Type: & Technical Paper \\
\hline Keywords: & $\begin{array}{l}\text { Emergency Services, Traumatic Stress, Psychological Surveillance, } \\
\text { Wellbeing }\end{array}$ \\
\hline
\end{tabular}




\title{
The role of psychological screening for emergency service responders
}

\begin{abstract}
Purpose: The purpose of this paper is to examine the role psychological screening and surveillance takes in improving the delivery of psychological support to emergency service responders (ESR) at a time of increasing demands and complexity.

Approach: To review the evidence for the psychological screening and surveillance of trauma exposed emergency service workers.

Findings: The evidence supports the use of psychological screening and surveillance using appropriate validated questionnaires and surveys.

Implications: The findings suggest that emergency services should be using psychological screening and surveillance of ESRs in roles with a high risk of traumatic stress.

Originality/Value: These findings will help emergency service organisations recognise how psychological screening and surveillance can be used as part of a wider programme of wellbeing support. This approach can also help them meet their legal Health \& Safety obligations to protect the psychological health and wellbeing of their ESRs.

Key Words: Emergency Services, Traumatic Stress, Psychological Surveillance, Wellbeing

Paper Type: Technical Paper
\end{abstract}

\section{Introduction}

UK Emergency Services have entered a period of unprecedented change, at a time of reduced budgets (National Audit Office, 2015a and 2015b), reduced manpower (HMIC, 2016), increasing demands (National Audit Office, 2017), and changes to the terms and conditions for their workers (Windsor, 2012; Hutton, 2011). The pace of these changes make organisational and operational adjustment difficult (Windsor, 2012; Simcock, 2015; National Audit Office, 2017). In addition, emergency service responders (ESRs) are dealing with mounting threats from terrorism, natural, and man-made disasters at a level and intensity rarely experienced in the past. There are pressures to increase joint working between emergency services, both strategically (HM Government, 2016) and operationally (ESCWG, 2016), with firefighters, police and paramedics taking over aspects of each other's roles. This move has not been without opposition, with firefighters and police finding the 
emotional labour of dealing with health-related emergencies, whilst surrounded by distressed and grieving families, difficult to handle. In policing, the combination of reduced resources, increased pressure and complex demands has led to higher levels of sickness absence (Guardian, 2016) and difficulties in the recruitment and retention of workers (National Health Executive, 2015).

The roles of those working in emergency services fall into three main categories (College of Policing, 2016). The first category are the frontline responders who are regularly involved in responding to incidents ranging from recovering stolen bicycles, transporting patients or checking smoke alarms, to dealing with murder, serious injuries, major fires, domestic violence, suicides and cot deaths. These same responders are often the first at the scene of major incidents such as terrorist attacks, rail crashes, riots and explosions. The main characteristic of traumatic exposure for the front-line responders is the unpredictability of the incidents they are required to handle. Emergency responders have little time to prepare to meet the operational and emotional demands of the incident, with the result that their ability to cope can become overwhelmed. The psychological impact of attempting to meet extreme physical, cognitive and emotional demands of a crisis can be the development of acute stress disorder, which may lead to post-traumatic stress (Shakespeare-Finch, 2011; Halpern et al. 2009).

The second category of ESRs include those working in roles involving intense exposure to psychological hazards, these specialists ESRs use their technical skills in high psychological risk areas of work. In policing these may include on-line child abuse, domestic violence, firearms, undercover work, accident investigations or family liaison. In these specialist roles the psychological risks are inherent to the role, creating a responsibility on the organisation to meet its legal duty of care to protect the wellbeing of these workers. This duty requires the emergency service to have plans and procedures in place to identify, monitor, reduce and respond to psychological hazards (Management of Health and Safety Regulations, 1999). ESRs working in specialist roles may experience a build-up of compassion fatigue and secondary trauma, which can go unnoticed, unrecognised and untreated, until the ESR finds 
themselves unable to cope due to the long term psychological harm caused by their work (Weiss et al. 2010).

The third category is made up of response and specialist ESR deployed to deal with a major disaster. Emergency services are well versed in handing the operational and practical challenges of major fires, floods, transport collisions and terrorist attacks involving mass death and casualties (Slottie et al. 2008). Comprehensive emergency preparedness guidance (Cabinet Office, 2012) sets the framework for civil protection dealing with preparation, management and prevention of emergencies. However, emergency services are less well prepared for dealing with the human impact of a disaster on their ESRs who are involved in disaster responses. Whilst most ESRs will handle the psychological impact of dealing with the demands of a major disaster, many will become affected, at least in the short term (Tehrani, 2016).

This paper has four aims:

1. To explain how physical and psychological screening and surveillance is used in organisations;

2. To provide an outline on meeting the needs of the response, specialist and disaster facing ESRs;

3. To describe the range of tools available to be used in screening and surveillance;

4. To discuss the reasons for introducing psychological screening and surveillance into emergency services.

\section{Use of Screening and Surveillance}

Health surveillance and screening has been used in emergency services to provide evidence to assist in the assessment, monitoring and support of ESRs fitness for work. Surveillance adopts a systematic approach to the early identification of work-related ill-health or injury (Mouthaan et al. 2014; Dantzker, 2011; Carleton, 2017; McFarlane and Bryant, 2007). The Management of Health and Safety at Work (1999) legislation provides the framework with a specific reference to the need for surveillance, 
"Every employer shall ensure that his employees are provided with such health surveillance as is appropriate having regard to the risks to their health and safety which are identified by the assessment." (Point 6).

Surveillance falls within the wider Risk Control and Management Cycle in which organisations are required by law to identify risks, establish who might be harmed, to evaluate the magnitude of the risk and to identify ways to mitigate or reduce the risks (IOSH, 2016). Occupational surveillance shares some of the features of clinical research, but is not designed to generate or create new scientific knowledge. Rather, it uses existing knowledge and research to prevent disease or injury, enhance resilience and increase wellbeing in employees who may become exposed to an identified health hazard (Otto et al. 2014). A review of the risks inherent in organisations (European Agency for Safety and Health at Work, 2011) identified a range of hazards found in emergency services, including physical exposures to radioactive, chemical and biological substances in addition to physical injuries caused by physical violence, needlesticks and injuries caused by knives and firearms. In addition to the physical hazards, the agency identified several psychological hazards. These include exposure to disasters, dealing with multiple deaths, body recovery, transport accidents, terrorism, fires, shootings and other threats to life. Psychometric testing is used for different purposes, in emergency services tests are often employed in pre-employment screening to assess a candidate's fitness to carry out their roles. The College of Policing (2015) has established standards for pre-employment screening which include an assessment of physical and psychological fitness, together with tests of aptitude and mental capacity. ESRs are required to have regular in-post checks of their stamina, sight and hearing (e.g. College of Policing, 2014).

The use of screening in psychological surveillance is different to the psychometric testing that takes place pre-employment, in contrast to the one-off pre-employment tests, psychological surveillance is an ongoing process used to assist in the maintenance of a healthy workforce where the results allow for ESRs to be tracked over time, identifying those with signs or symptoms indicative of actual or imminent psychological difficulties. An important issue for screening and surveillance programmes is the reliability and validity of the tools employed (Mouthaan et al. 2014). Psychological tests need to demonstrate that they accurately measure the magnitude of a psychological condition or feature over time and population. In addition, these tools need to be able to differentiate between ESRs 
experiencing significant early signs of psychological distress from those within a normal range of emotional expression. A benefit of a surveillance approach is that it allows for the sensitivity of the cut-off levels to be adjusted informed by organisational feedback on levels of sickness absence and occupational health referrals together with the proportion of ESR referrals deemed appropriate at clinical assessment. The surveillance approach recognises that mental health is a continuum, where the boundary between and coping and not coping with pressures of emergency work may be very narrow.

There are some researchers working with the UK military (e.g. Rona et al 2006; Greenberg, 2015) who suggest that pre-employment screening is ineffective in reducing or predicting PTSD, and that screening can adversely affect the career of those identified as vulnerable (Jones et al. 2003). This negative view of screening is challenged by US military researchers (Castro; 2014; Milliken et al. 2007), who utilise screening for the early identification of mental health problems, and in programmes of education and support. In the US screening is used to increase wellbeing and resilience by reducing psychological stigma and barriers to seeking support. Wright et al. (2007) described psychological screening as one of the most widely used ways to identify [US] military personnel who might need help for a mental health issue.

\section{Meeting the Needs of Emergency Service Responders (ESRs)}

\section{Front-line Responders}

The largest group of ESR are the frontline responders. For this group the nature and frequency of the traumatic exposure is difficult to predict. However, the types of the traumatic events causing trauma responses together with the organisational and personal factors that increase vulnerability are largely understood (Skogstad et al, 2013). As frontline responders do not face predictable traumatic events it is inappropriate for them to be part of a surveillance programme, as their results can provide data which can be misleading and costly (HSE, 1999). Therefore, the responsibility for the psychological wellbeing of frontline responders falls to their line manager and the ESRs themselves. The line managers of frontline responders need to be trained in identifying the signs of mental health problems (including traumatic stress), to have the skills to talk to their team about any personal 
difficulties, personal resilience, and to create an environment where open discussion of work related problems is seen as a strength rather than a weakness (Hesketh \& Cooper, 2017). The frontline responders need comprehensive induction training to prepare them for the nature of their role and the incidents that may cause a trauma response (Castro et al, 2006), they also need to be able to recognise symptoms of trauma in themselves and others. A study undertaken for the Health and Safety Executive by Mitchell \& Stevenson (2000) found that supportive supervisors with a positive management approach, a workforce educated in the recognition of psychological signs and symptoms, together with flexible psycho-social support, reduced the likelihood of psychological problems. When a front-line responder returns from a shift it is important that time is made available for them to be demobilised by their line manager. The demobilising process takes between $5-10$ minutes (Tehrani, 2014). If the team leader recognises that a responder has been seriously affected by an incident there may be a need to arrange a longer demobilising session, which provides the responder with an opportunity to talk about the incident that has caused the difficulty, and to be provided with helpful psycho-education and advice (Tehrani, 2014). Where responders continue to struggle, their line manager should make a referral to Occupational Health, who can refer the ESR for psychological screening to identify if there is a need for a psychological assessment or other supportive intervention. The provision of organisational demobilisation and defusing following a traumatic incident has been shown to meet several needs for teams, by providing a) support that is highly valued by workers; b) an opportunity to identify workers requiring clinical support; c) an increase in level of social cohesion; d) a reduction in harmful responses e.g. alcohol abuse; e) a reduced levels of sickleave; f) increased performance (Creamer et al. 2012).

\section{Specialist Responders}

There is a relatively small group of ESRs, who are employed in roles which continually expose them to psychologically distressing or demanding conditions. Risk assessments have identified the roles which carry the highest psychological burden. In Policing, for example, these include: family liaison, call handling, undercover investigations, public protection, viewing on-line images of child abuse, firearms, hostage negotiators and body recovery. Emergency services have to respond to the needs of these ESRs by introducing mandatory risk assessments, psychological screening and support to meet their duty of care 
(Management of Health and Safety Regulations, 1999). Craun et al (2014) undertook research to examine the level of secondary traumatic stress in law enforcement officers involved in the investigation of sex offences, and found that the development of PTSD, secondary trauma and compassion fatigue was reduced where there was positive supervisor support, and increased where there were high levels of denial. Research by Carleton et al. (2017) involving the screening of 5813 Canadian ESRs (police, paramedics, firefighters and prison officers) for PTSD, anxiety, depression, social anxiety, panic disorder and alcohol abuse found that there was an indication of at least one of the disorders in $44.5 \%$ of the ESRs. Wortley et al. (2014) studied internet child abuse investigators. This study used a combination of screening questionnaires and interviews which showed that whilst the majority had no clinically significant symptoms, there were a number experiencing significant levels of PTSD a risk that appeared to increase over time. Whilst these research projects on the psychological impact of the roles undertaken by ESRs provides vital information on the nature of psychological exposure and distress, they should not be confused with psychological surveillance.

The case for a national screening and surveillance programme of workers exposed to traumatic incidents was proposed by Dollard et al (2007), who support the use of surveillance for monitoring and tracking how the nature and management of work creates challenges for the occupational health and safety of workers. Essential to the introduction of surveillance programmes is the development of screening tools, with clearly defined cutoff levels which can be used to identify those ESRs needing further psychological support and assessment (McFarlane \& Bryant, 2007). The need for psychological surveillance in ESRs was identified in the late 1990s, on-line screening and surveillance for specialist roles has made this more feasible (Price et al., 2016). The surveillance programme measures a range of clinical symptoms, including anxiety, depression, PTSD, burnout and compassion fatigue; with ESRs being screened pre-deployment and at regular intervals throughout their specialist deployment. Initial screening shows that around $80 \%$ of ESRs in specialist roles are fit and have no significant symptoms of trauma, 15\% have scores which are concerning and $5 \%$ have clinically significant symptoms of PTSD (Tehrani, 2016a). The screening results do not halt deployment, but rather they trigger a psychological assessment which can be used to provide psycho-social education and advice, a referral for trauma therapy and occasionally a redeployment to an alternative role (College of Policing, 2018). Surveillance 
of child protection officers (Tehrani, 2018) examined the results from 2289 officers and showed that attitudes to health, tenure and adverse childhood experiences were associated with increased clinical scores. In another surveillance report involving 126 internet child abuse investigators (Tehrani, 2016), it was found that there were higher levels of secondary traumatic stress in female investigators, and in investigators who were introverted or neurotic. The role of surveillance is not, in itself, to reduce the incidence of mental health problems. Rather, it is a supportive measure to identify risk and resilience factors within the working environment, and to identify where and individual ESR requires support or further assessment. As with the frontline responders, the line manager's role is important in providing a supportive environment in which it is acceptable for ESRs to discuss their work and the challenges it creates in personal and working life. The line manager should also make a referral to occupational health where there is a need for additional assessment and support.

\section{Disaster Responders}

Large numbers of frontline and specialist ESR are needed to deal with major incidents and disasters, and depending on their level of exposure, many will require psychological support (BPS, 2018). As with the frontline responders, it is important to provide immediate practical support at the time of the disaster, and to ensure that ESRs are demobilised at the end of each shift. Although debriefing is designed to prevent or treat PTSD (Regel \& Dyregrov, 2012; Ruck et al. 2013), these interventions are highly valued in building social cohesion and support (Dyregrov, 2002). Debriefing meets the needs of ESRs to have their experiences recognised in a familiar setting, where they can be provided with psycho-education, support and the opportunity to reflect on their experiences with their colleagues. Although the use of debriefing has been challenged as a treatment for PTSD (Bisson et al. 2000), this does not detract from the role debriefing can play in providing an early indication of those requiring further assessment and support (Arendt \& Elklit, 2001).

There is mounting evidence to show that undertaking brief screening can be helpful in identifying ESRs who are likely to require psychological support. It is recognised that in the immediate aftermath of a disaster most people will have experienced heightened responses (Sijbrandij et al 2008), and that these responses will rapidly decline over time. However, for some ESRs the symptoms do not decline, and may become more intense. There has been 
some success in developing brief post-trauma screening tools which have a high level of sensitivity and specificity in accurately identifying people likely to develop PTSD (Brewin et al 2008; Mouthaan et al 2014). The screen and treat approach has the benefit of identifying ERSs who need to be referred to occupational health for a more comprehensive screening and psychological assessment.

\section{Screening and Surveillance Tools}

There is a wide range of psychological questionnaires which can be used to identify levels of trauma and clinical wellbeing (ACPO, 2007). Table 1 provides a list of some of those commonly used in the screening and surveillance process. The list of tools has been divided into four main groups:

a) Critical incident screening tools which involve self-report questionnaires that can be used after a critical incident as a way of identifying ESR who need to be referred for further investigation. The sensitivity and specificity of the shorter tools have been shown to be as good as the longer tools (Sijbrandij et al 2008), therefore it would seem appropriate to use the shorter tools as these are more likely to be completed. There is a growing tendency for these questionnaires to be completed on smartphones.

b) Clinical assessment tools are also self-report tools and are often completed online for ease of scoring and analysis. The PCL-5 and PSS-5 are similar, in that they are based on the latest version of the Diagnostic and Statistical Manual's criteria for PTSD (APA, 2013). Traumatic exposure can also lead to clinical levels of anxiety, depression, burnout and secondary trauma, tools which measure these conditions also need to be part of any screening/surveillance programme. Dissociation is a common state following a traumatic exposure. Tools to measure post-trauma dissociation (DESII) and peritraumatic dissociation (PDEQ) are included in Table 1.

c) An assessment of associated personal and work-related factors is also included in a surveillance programme as these provide some indication of what makes some ESRs more vulnerable to becoming affected by traumatic events. This additional information is useful when designing interventions to be used to increase resilience and help to develop training and education programmes. Adverse childhood 
experiences, personality, sense of purpose, coping styles and work engagement have all been found to be related to the magnitude of trauma symptoms.

d) For the small number of ESRs that require trauma treatment it is important to have suitable diagnostic tools. The CAPS-5 is seen as the gold-standard tool for diagnosis but this can only be administered by a clinician qualified in administering and interpreting this scale. The PSS-I-5 can be used for a similar function. (A diagnosis of PTSD is necessary when seeking medical retirement). However, for trauma psychologists and therapists the use of formulation and psychological assessment are more appropriate tools as these lead to the development of post trauma interventions and support.

Note: Psychological screening and surveillance tests are protected, and the disclosure of test materials is prohibited, as the unauthorised access to psychometric test material erodes their validity and reliability. There is also a need for anyone involved in the administration or interpretation of screening results to be appropriately qualified. In addition, there are strict rules relating to the confidentiality of the results and the protection of this data from unauthorised access.

\section{Discussion}

It is recognised that there are increasing pressures being placed on emergency services to deal with the trauma of terrorism, natural and manmade disasters, interpersonal violence and personal tragedies. Alongside, there is a continual reduction in funding and an increase in workload, challenging the ability of the ESR to remain resilient and cope with the psychological burden. More frequently, internal support resources are stretched to their limits, with precious occupational health resources needing to be targeted effectively. There is a requirement for management and ESRs to become emotionally aware, and to have the knowledge and training in identifying the signs and symptoms of stress and trauma in themselves and their colleagues. If society is to be kept safe, emergency services must maintain their capability for dealing with emotionally challenging, complex and traumatic work, and introduce organisational systems and processes which meet the organisational, operational and personal needs of ESRs. 
To be successful there is a need for the development of trauma informed organisational policies and procedures for dealing with disasters and other critical incidents, and for providing support to those affected (Bloom, 1997). Emergency services need to deliver trauma awareness training and education to supervisors and ESPs. This is critical when recognising and responding to signs and symptoms of traumatic stress, and is needed to provide evidence-based early interventions and regular screening and support to identify those who are struggling, as a means of reducing stigma and building wellbeing and trauma resilience (McFarlane \& Bryant, 2007). This approach is being supported by Blue Light Framework (Hesketh \& Williams, 2017), which aims to improve the psychological wellbeing of emergency service responders. Guidance on risk assessment and screening in emergency services which promotes a systematic approach to supporting ESRs (Hesketh et al, 2017) and on managing trauma in high risk organisations (Hesketh \& Tehrani, 2018).

Psychological screening and surveillance of ESRs provides a simple and economic mechanism to identify ESRs in need of psychological support, and an opportunity to examine and quantify the impact of personal and organisational factors. These will, in turn, be influencing the level of trauma resilience with the aim of creating a workforce which is trained and equipped to recognise and build their psychological wellbeing; and for the emergency services to meet their duty of care by proactively promoting a trauma informed workforce.

\section{References}

ACPO (2007) Combating Child Abuse on the Internet (CCAl): Practice Advice on the Protection of Workers Engaged in Identifying, Investigating, Tracking and Preventing online Child Sexual Abuse, Association of Chief Police Officers

APA (2013) Diagnostic and Statistical Manual of Mental Disorders (fifth addition), Arlington, American Psychiatric Association

Antanovski, A. (1996) The salutogenic model as a theory to guide health promotion, Health Promotion International, 11 (1) 11-18

Arendt, M., Elklit, A., (2001) Effectiveness of psycholgoical debriefing, ACTA Psychatrica, Scandinavia, 104, 423-437

Basoglu M. Salcioglu, E. :ovampi, M. Cyzeren, M. Aker, T. Kilic, C. Mestcioglu, O (2001) A study of the validity of a screening instrument for traumatic stress in earthquake survivors in Turkey, Journal of Traumatic Stress, 14 (3) 491-509 
Bisson, J.L. McFarlane, A.C. Rose, S. (2000) Psycholgoical Debriefing. In Foa E.B. Keane, T.M. Friedman,M.J. Eds. Effective Treatments of PTSD. New York, Guildford Publicaitons 3959

Bloom, S (1997) Creating Sancturary, London, Routledge

BPS (2018) How can psychology inform disaster management, Leicester, British Psychological Society.

Brewin, C. R., Rose, S. Andrews, B. Green, J. et al (2002) A brief screening instrument for post trauamtic stress disorder. British Journal of Psychiatry, 181, 158-162

Brewin, C.R., Scagg, P. Robertson, M. Thompson, M. et al. (2008) Promoting mental health following the London bombings: a screen and treat approach, Journal of Traumatic Stress, 21 (1) 3-8

Cabinet Office (2012) Emergency Preparedness, https://www.gov.uk/government/publications/emergency-preparedness downloaded 18.02.2018

Carleton, R.N., Afifi, T.O. Turner, S. Taillieu, T. Duranceau, S.LeBouthiller, D. Sareen, J. et.al (2018) Mental disoarder symptoms among public safety personnel in Canada, The Canadian Journal of Psychiatry, 63(1) 54-64

Carlson, E.B. Putnam, F.W. (1993) An update on the dissociative experiences scale, Dissociation, 6, 16-26

Carver, C.S. Scheier, M.F. Weintraub, J.K. (1989) Assessing coping strategies: a theoretical based approach, Journal of Personality and Social Psychology, 56 267-283

Castro, C.A. Hoge, C.W. Cox, A.L. (2006) Battlemind training: building soldier resiliency. In Human dinensions in Military Operations - Military Leaders' strategies for addressing stress and psycholgoical support. pp42-1 - 42-6, Meeting proceedings Neuilly-sur-Seine,

Castro, C.A. (2014) The US framework for underrstanding, preventing and caring for the mental health needs of service members who served in combat in Afghanistan and Iraq: a brief review of the issues and the research; The European Journal of Psychotraumatology, 5 :24713 -http//dx.doi.org/10.3402/ejpt.v5.24713

College of Policing (2018) Responding to Trauma in Policing: a practical guide, Coventry, College of Policing. https://oscarkilo.org.uk/responding-trauma-policing-new-collegeguidance/ downloaded 18.02.2018

College of Policing (2016) Psychological Risk Management: Introduction \& Guidance, Coventry, College of Policing Ltd. https://oscarkilo.org.uk/wp-content/uploads/2017/05/Psychological-RiskManagement-v6.pdf downloaded 18.02.2018

College of Policing (2015) Recruit Assessment Centers for Police Constables. http://recruit.college.police.uk/Officer/after-l-apply/Pages/Constables-AssessmentCentre.aspx downloaded 18.02.2018

College of Policing (2014) Job Related Fitness Tests. http://www.college.police.uk/What-wedo/Standards/Fitness/Documents/PoliceFitnessGuidance.pdf downloaded 18.02.2018 
Craun, S.W. Bourke, M.L. Bierie, D.M. Williams, K.S. (2014) A longitudinal examination of secondary traumatic stress among law enforcement, Victims and Offenders, 9, 299-316

Creamer, M.C. Varker, T. Bisson, J. Darte, K. Greenberg, N. Lau, W. Moreton, G. O’Donnell, M.

Richardson, D. Ruzek, J. Watson, P. Forbes, D. (2012) Guidelines for Peer Support in HighRisk Organisations: an international consensus study using the Delphi Method, Journal of Traumatic Stress, 25, 134-141

Dantzker, M.L. (2011) Psychological pre-employment screening for police candidates seeking consistency if not standardisation, Professional Psychology, Research and Practice, 42, 3, 276-283

Dollard, M. Skinner, N. Tuckey, M Bailey, T. (2007) National surveillance of psychosocial risk factors in the workplace: An international overview Work and Stress 21(1):1-29

Dyregrov, A. (2002) Psychological Debriefing: a leader's guide for small group crisis intervention, Ellicott City, MD. Chevron Publishing

Ehlers \& Clark (2000). A cognitive model of posttraumatic stress disorder. Behaviour Research \& Therapy, 38(4), 319-345.

ESCWG (2016) Emergency Services Collaboration Working Group National Overview, https://aace.org.uk/wp-content/uploads/2016/11/National-overview-v13-WEB.pdf, downloaded 18.02.2018

European Agency for Safety and Health at Work (2011) Emergency Services: a literature review on occupational safety and health risks, Luxembourg, Publications office of the European Union.

Eysenck, SBG, Eysenck, HJ Barrett PA (1985) A revised version of the psychoticism scale, Personality Individual Differences, 6 (1) 21-29

Felitti MD, Anda RF, Nordenberg MD, et al. (1998) Relationship of childhood abuse and household dysfunction to many of the leading causes of death in adults: the Adverse Childhood Experiences (ACE) Study. American Journal of Preventive Medicine; 14: 245258

Foa, E \& Tolin, DF (2000). Comparison of the PTSD Symptom Scale-Interview Version and the Clinician-Administered PTSD Scale. Journal of Traumatic Stress, 13, 181-191

Goldberg, D, Bridges, K. Duncan-Jones, P.Grayson, D. (1988) Detecting anxiety and depression in general medical settings, British Medical Journal, 297, 897-899

Greenberg, N (2015) Psychological impact of traumatic events: guidance for traumaexposed organisations, Occupational Health at Work, 12 (1) 17-21

Guardian (2016) Police Sick-leave for Psychological Reasons up by a Third in Five Years. 05/04/2016 https://www.theguardian.com/uk-news/2016/apr/05/police-sick-leave-forpsychological-reasons-up-by-a-third-in-five-years downloaded 18.02.2018

HSE (1999) Health Surveillance, HSG61, Norwich, HSE Books

Halpern, J. Gurevich, M. Schwartz, B. Brazeau, P. (2009) What makes an incident critical for ambulance workers? Emotional outcomes and implications for intervention, Work \& Stress, 23, (2) 173-189 
Hesketh, I., Williams, S. (2017). 'Blue Light Wellbeing Framework.' College of Policing Ltd. Retrieved from: https://oscarkilo.org.uk/wellbeing-framework/ downloaded 18.02.2018

Hesketh, I., Tehrani, N., Harrison, J. (2017). Psychological Risk Management: Introduction \& Guidance. College of Policing Ltd. Retrieved from: https://oscarkilo.org.uk/wpcontent/uploads/2017/08/FINAL-Psychological-risk-management.pdf downloaded 18.02.2018

Hesketh, I., Cooper, C. (2017) Measuring the People Fleet: General Analysis, Interventions and Needs. Strategic HR Review. 16 (1) pp 17-23

Hesketh, I., Cooper, C. (2017). Managing Health and Well-Being in the Public Sector: A Guide to Best Practice. Routledge Psychology Press.

Hutton, W. 2011. Independent Public Service Pension Commission. London: HM Treasury.

HM Government (2016) Enabling Closer Working Between the Emergency Services

Summary of consultation responses and next steps, https://www.gov.uk/government/uploads/system/uploads/attachment_data/file/4953

71/6.1722_HO_Enabling_Closer_Working_Between_the_Emergency_Services_Consult.. ..pdf downloaded 18.02.18

HMIC (2016) The state of policing; The annual assessment of policing in England and Wales 2015,.London, Her Majesties Inspectorate of Policing https://www.justiceinspectorates.gov.uk/hmicfrs/publications/state-of-policing-theannual-assessment-of-policing-in-england-and-wales-2016/ downloaded 18.02.2018

IImarinen, J. (2007) The Work Ability Index (WAI), Occupational Medicine, 57160

IOSH (2016) Occupational health management in the workplace A guide to the key issues of occupational health provisions, Wigston, IOSH

Jones, E. Hyams, K.C. Wessely, S. (2003) Screening for vulnerability to psychological disorders in the military: a historical survey, Journal of Medical Screening, 10 (1) 40-46

McFarlane, A.S. Bryant, R.A. (2007) Post-traumatic stress disorder in occupational settings: anticipating and managing the risk, Occupational Medicine. 57, 404-410

Management of Health and Safety Regulations (1999) Management of Health and Safety Regulations http://www.legislation.gov.uk/uksi/1999/3242/body/made?view=plain Accessed: 02.04.2018

Marmar CR, Metzler TJ, Otte C (2004): The Peritraumatic Dissociative Experiences Questionnaire. Assessing Psychological Trauma and PTSD: A Handbook for Practitioners. Edited by: Wilson JP, Keane TM. New York, NY: Guilford Press, 144-167

Milliken, C.S. Auchterlonie, J.L. Hoge, C.W. (2007) Longitudinal Assessment of mental health problms among active and reserve component soldiers returning from the Iraq war, JAMA. 2007;298(18):2141-2148. doi:10.1001/jama.298.18.2141

Mitchell, M. Stevenson, K. (2000) Managing post incident reactions in the police service, Caerphilly, HSE

Mouthaan, J. Suhbrabduj, M. Reitsma, J.B. Gersons, B. P. R. Oliff, M. (2014) Comparing Screening Instruments to Predict Posttraumatic Stress Disorder, Plos 1, 9, (5) 97183 National Audit Office (2015a) Financial Sustainability of Police Forces in England and Wales. 
https://www.nao.org.uk/wp-content/uploads/2015/06/Financial-sustainability-of-policeforces.pdf downloaded 18.02.2018

National Audit Office (2015b) Impact of funding reductions on fire and rescue services, https://www.nao.org.uk/report/impact-of-funding-reductions-on-fire-and-rescueservices/ downloaded 18.02.2018

National Audit Office (2017) NHS Ambulance Services, https://www.nao.org.uk/wpcontent/uploads/2017/01/NHS-Ambulance-Services.pdf downloaded 18.02.2018

National Health Executive (2015) Rate of Paramedics leaving ambulance service nearly doubles http://www.nationalhealthexecutive.com/News downloaded 17.02.2018

Otto, J.L. Holodniy, M. DeFraites, R.F. (2014) Public Health Practice is not research, American Journal of Public Health, 104 (4) 596-602

Price, M. Kuhn, E. Hoffman, J.E. Ruzek, J. Acierno, R. (2015) Comparison of the PTSD checklist (PCL) administered by mobile device relative to paper form. Journal of Traumatic Stress, 28 (5) 480-483

Regel, S. Dyregrov, A. (2012) Commonalities and New Directions in Post-trauma Support Interventions: from Pathology to the Promotion of Post-traumatic Growth, In R. Hughes, A. Kinder \& C.Cooper, Eds. International Handbook of Workplace Trauma Support, Chichester, Wiley-Blackwell

Rona, R. Hooper, R. Jones, M. Hull, L. Browne, T. Horn, O. Murphy, D. Hotopf, M. Wessely, S. (2006) Mental health screening in armed forces before the Iraq war and prevention of subsequent psychological morbidity: follow up study British Medical Journal 333:991

Ruck, S. Bowes, N. Tehrani, N. (2013) Evaluating trauma debriefing within the UK prison service, The Journal of Forensic Practice, 15 (4).281-290

Shakespeare-Finch, J. (2011) Primary and secondary trauma in emergency personnel. Traumatology, Vol 17(4)

Schaufeli, W.B. Bakker A.B. (2006) The measurement of work engagement with a short questionnaire, Educational and Psychological Measurement, 66 (4) 701-716

Sijrandij, M. Oliff, M. Opmeer, B.C. Carkuer, I.V.E. Gersons, B.P.R. (2008) Early prognostic screening for posttraumatic stress disorder with the Davidson Trauma Scale and the SPAN. Depression \& Anxiety, 25 1038-1045

Simcock, T. (2015) Evidencing organisational change in the UK Fire and Rescue Services, Fire Protection, Oct 44-45

Skogstad, M. Slorstad, M. Lie, A. Conradi, H.S. Heir, T. Weisaeth, L. (2013) Work-related post-traumatic stress disorder. Occupational Medicine, 2013; 63:175-182

Slottje, P. Witteveen, A.B. Twisk, J.W.R., Smidt, N. Huizink, A.C. Mechelen, W. Smid, T. (2008) Post disaster physical symptoms of firefighters and police officers: Role of types of exposure and post-traumatic stress symptoms. British Journal of Health Psychology, 13, 327-342

Spitzer RL, Kroenke K, Williams JB, et al;(2006) A brief measure for assessing generalized anxiety disorder: the GAD-7. Arch Intern Med. 22;166 
Stamm, B.H. (2010) The concise ProQOL manual, Pocatello, ID, ProQOL.org.

Tehrani, N. Cox, T. Cox S. (2002) Assessing the Impact of stressful events in organisations: the development of an extended impact of events scale, Counselling Psychology Quarterly 15, 2, 191-200

Tehrani, N. Maclntyre, B. Maddock, S. Shaw, R. Illingworth, R. (2007) Rehabilitation: Maintaining a healthy workforce. In Scott McIntye \& Jonathan Houdmont (eds) Health Psychology- European perspectives on research, education and practice. SerSilito Maia, ISMAI

Tehrani, N. (2014) Trauma, Resilience and Growth, Occupational Health and Wellbeing, April https://www.personneltoday.com/hr/trauma-resilience-growth/ downloaded 18.02.2018

Tehrani, N. (2016) Counselling Psychology for Trauma in Emergency Service Occupations In David Murphy Ed. Counselling Psychology: a textbook for study and practice, Chichester, Wiley

Tehrani, N. (2016a) Extraversion, neuroticism and secondary trauma in Internet child abouse investigators, Occupational Medicine, 66 (5) 403-407

Tehrani, N. (2018) Child Protection: long-term implications on psychological wellbeing and workability. Occupational Medicine, kqy016 doi:10.1093/occmed

Tuckey, M., \& Scott, J. E. (2014). Group critical incident stress debriefing with emergency services personnel: A randomized control trial. Anxiety, Stress and Coping, 27(1), 38-54

Weathers, F. W., Litz, B. T., Keane, T. M., Palmieri, P. A., Marx, B. P., \& Schnurr, P. P. (2014). PTSD Checklist for DSM-5 (PCL-5). National Center for PTSD. http://www.ptsd.va.gov/professional/assessment/adult-sr/ptsd-checklist.asp

Weiss, D.S. Bruner, A. Best, S.R. Metzler, T.J. Liberman, A. Pole, N. Fagan, J.A. Marmar, C.R. (2010) Frequency and severity approaches to indexing exposure to trauma: the critical incident history questionnaire for police officers, Journal of Traumatic Stress, 23 (6) 734-743

Weiss, D.S., Marmar, C.R. (1997) The impact of events scale-revised, In Wilson J.P. Keane, T.M. eds. Assessing psychological trauma and PTSD, New York, Guildford Press, pp399411

Winsor T. (2012) Independent Review of Police Officer and Staff Remuneration. http://webarchive.nationalarchives.gov.uk/20130312170837/http://review.police.uk/p ublications/part-2-report/ downloaded 18.02.2018

Wortley, R., Smallbone, S, Powell, M. Cassematis, P. (2014) Understanding and managing the occupational health impacts on investigators of internet child abuse, Brisbane, Griffith University; 2014

Wright, K.M., Bliese, P.D., Thomas, J.L., Adler, A.B. Eckford, R.D. Hoge, C.W. (2007)

Contrasting approaches to psychological screening with U.S. combat soldiers, Journal of Traumatic Stress, 20 (6) 965-975 
Table 1: Examples of some screening and surveillance tools available for assessing post trauma responses

\begin{tabular}{|c|c|c|c|}
\hline Post Critical Incident Screening Tools & Developer & Features & Cut-off score \\
\hline Traumatic Stress Symptom Checklist (TSSC) & Basoglu et al. 2001 & 23 items 17 trauma items and 6 depression items. Four- point scale & 25 or higher \\
\hline The Impact of Events Scale-Revised (IESE-R) & Weiss \& Marmar, 1997 & 22 items which measure intrusion, avoidance and hyperarousal. Five-point scale. & Varied \\
\hline The Trauma Screening Questionnaire (TSQ) & Brewin et al., 2002 & 10 items. Five intrusion items and five hyperarousal items. Yes/No scale & 6 or higher \\
\hline The Davidson Trauma Scale (DTS) & Sijbrandij et al 2008 & $\begin{array}{l}17 \text { items rated for frequency and severity during the previous week. Five-point } \\
\text { scale }\end{array}$ & 20 or higher \\
\hline SPAN (short form of DTS) & Sijbrandij et al 2008 & 4 items Startle, Physiological Arousal, Anger and Numbness. Five-point scale & 5 or higher \\
\hline Clinical Assessment Tools & Developer & Features & Cut-off score \\
\hline PTSD Checklist 5 (PCL-5) & Weathers et al, 2014 & 20 items 5 re-experience, 2 avoidance, 7 neg. self-belief, 6 arousal five-point scale & 33 or higher \\
\hline PTSD Symptom Scale (PSS-5) & Foa \& Tolin, 2000 & 20 items 5 re-experience, 2 avoidance, 7 neg. self-belief, 6 arousal five-point scale & 33 or higher \\
\hline Impact of Events Scale - Extended (IES-E) & Tehrani et al, 2002 & 23 items which measure intrusion, avoidance and hyperarousal. Five-point scale. & 50 or higher \\
\hline General Anxiety Disorder-7 (GAD-7) & Spitzer et al, 2006 & 7 items which measure anxiety. Four-point scale & 10 or higher \\
\hline Goldberg Anxiety/Depression Scale & Goldberg et al. 1988 & 9 items anxiety items and 9 depression items Yes/No scale & 5 or more both items \\
\hline Peritraumatic Dissociative Experiences (PDEQ) & Marmar et al 2004 & 10 items Five-point scale & 12 or higher \\
\hline Dissociative Experiences Scale II (DESII) & Carlson \& Putnam 1993 & 28 items scored on $\%$ of time symptom experienced & $30 \%$ or higher \\
\hline Professional Quality of Life-Revised (ProQOL R) & Stamm, 2010 & $\begin{array}{l}30 \text { items } 10 \text { compassion satisfaction (CS), } 10 \text { burnout (BO), } 10 \text { compassion fatigue } \\
\text { (CF) six- point scale }\end{array}$ & $\begin{array}{l}\text { CS } 30 \text { or lower, BO } 31 \text { or } \\
\text { higher, CF } 15 \text { or higher }\end{array}$ \\
\hline Resilience Assessment Tools & & \multicolumn{2}{|l|}{ Features } \\
\hline Adverse Childhood Experiences (ACE) & Felitti et al 1998 & \multicolumn{2}{|c|}{$\begin{array}{l}5 \text { items measure adverse childhood experiences and } 5 \text { items measure childhood adversity Yes/No } \\
\text { scale (Score of } 4 \text { or more are significant) }\end{array}$} \\
\hline Sense of Coherence (SoC) & Antovsky, 1996 & \multicolumn{2}{|l|}{13 items 4: meaningfulness, 5 comprehensibility, 4 manageability. Seven-point scale } \\
\hline $\begin{array}{l}\text { Eysenck Personality Questionnaire-Revised } \\
\text { (EPQ-R) }\end{array}$ & Eysenck et al. 1985 & \multicolumn{2}{|c|}{$\begin{array}{l}60 \text { items } 5 \text { subscales, extraversion/introversion, sensitivity (neuroticism), tough-mindedness } \\
\text { (psychoticism), social desirability and impulsivity. }\end{array}$} \\
\hline Cope Inventory & Carver et al, 1989 & \multicolumn{2}{|c|}{$\begin{array}{l}13 \text { coping subscales some are active and others passive. This measure is useful when taken } \\
\text { together with data from other measures where it can identify coping styles and tendencies. }\end{array}$} \\
\hline Utrecht Work Engagement (UWE) & $\begin{array}{l}\text { Schaufeli \& Bakker } \\
2003\end{array}$ & \multicolumn{2}{|c|}{$\begin{array}{l}3 \text { engagement scales, vigour, dedication, and absorption. The UWE has shown that some people } \\
\text { can be engaged in their work and become burnt out due to being over conscientious or driven to } \\
\text { succeed. }\end{array}$} \\
\hline Work Ability Score (WAS) & IImarinen, 2007 & \multicolumn{2}{|c|}{$\begin{array}{l}\text { A single item measures work ability. It has been taken from the Work Ability Index and has similar } \\
\text { predictive qualities for physical and psychological wellbeing. }\end{array}$} \\
\hline Diagnosis/Formulation Tools & Developer & \multicolumn{2}{|l|}{ Features } \\
\hline Clinician Administered PTSD Scale-5 (CAPS-5) & Weathers et al 2014 & \multicolumn{2}{|l|}{ CAPS-5 is a 30 -item structured interview (Gold Standard for trauma diagnosis) } \\
\hline PTSD Symptom Scale (PSS-I-5) & Foa \& Tolin, 2000 & \multicolumn{2}{|l|}{ PSS-I-5 is the 20 -item structured interview version of the PSS- 5 using the same questions } \\
\hline PTSD Formulation & Ehlers \& Clark, 2000 & \multirow{2}{*}{\multicolumn{2}{|c|}{$\begin{array}{l}\text { Formulation based on cognitive model of trauma by Ehlers \& Clark } \\
\text { Structured interview and assessment process which builds on access to a comprehensive psychologica } \\
\text { screening }\end{array}$}} \\
\hline Psychological Assessment of PTSD & Tehrani et al, 2007 & & \\
\hline
\end{tabular}

